\title{
End of the line for smallpox virus?
}

An article on page 748 of this issue raises the question whether remaining stocks of smallpox virus should be physically destroyed. That option, chiefly symbolic, should not be followed - just yet.

HERE is an intellectual gift (and puzzle) for the impending holiday season: now that the nucleotide sequence of the smallpox virus is completely known, and the details incorporated in the appropriate databanks, should not the remaining stocks of smallpox virus be destroyed? The case for doing so is simple. Stocks of the virus are potentially a danger, even potential sources of general re-infection of the human population, so long as they continue to exist. So much is clear from the British incident at Birmingham in 1978, when injudicious manipulation of the virus in a university laboratory led to the death of a technician and the subsequent suicide of the academic responsible. In principle, the consequences of the accidental release of smallpox organisms into the general population would now be greater: vaccination against smallpox was abandoned throughout the world in 1985 (most countries had given up the practice much earlier) so that a substantial fraction of all populations now lack immunity.

There is a further argument for destruction. The eradication of smallpox is a bright feather in the cap of World Health Organization (WHO), which set eradication as a goal in 1967 and, with meticulous if costly enthusiasm, set about the attainment of its goal. Who says that international organizations never achieve anything worthwhile? There has been no report of a natural case of smallpox since 1977 (in Somalia). And success has brought two benefits: a disease that as recently as a century ago killed a quarter of a million people a year in Europe alone is no longer a public health problem, and we have a shining example of how it is possible to eliminate infectious diseases altogether, given time, energy and a little luck. (Smallpox was an obvious target because of the high risk that an infected person would be killed, and an attainable one because vaccines are effective prophylactics).

The article now published was stimulated by a meeting in 1986 of a WHO specialist group which recommended that existing stocks of smallpox virus should be destroyed once the nucleotide sequence had been determined. The argument was that techniques even then available would allow the reconstruction of the virus from the known nucleotide sequence. What was true in 1986 is even more true now. So why not fall in with the notion that existing stocks of smallpox virus (at Atlanta and Moscow, the only two repositories of intact virus left) should be destroyed? One reason is general in character. Destroying the existing stocks would be symbolic only. Is there any reason to fear that the Centers for Disease Control at Atlanta and the Institute for Viral
Preparations in Moscow will be less than zealous in safeguarding the material in their freezers?

The arguments against disposal vary in their seriousness, but all turn on the possibility that the human race will be reinfected by smallpox at some stage in the future, when the tools for typing the strains of virus in circulation would be needed urgently. That might happen when corpses, by chance infected with smallpox, are recovered from the permafrost of, say, Siberia and examined in the laboratory. The chances of that happening are slim, but it is technically possible.

The more likely route to reinfection with smallpox or something like it is that one of the existing poxviruses may mutate to acquire the virulence of smallpox. There are several candidates of which the most obvious is the monkeypox virus, which can already infect people as well as monkeys. (The sole host of smallpox virus is the human being, which is one reason why rapid eradication has been possible.) Now that smallpox has disappeared from the list of conditions that diagnostic physicians include among the ailments that may affect their patients, it is likely that reinfection by either route or some other would have spread beyond the person first infected, whereupon there would be a panic. Against that remote possibility, it would be comforting to know that, if necessary, authentic samples of the smallpox virus plaguing recent centuries could be reconstructed quickly from the nucleotide sequence or, more probably, from the clones of sub-sequences of the viral genome that have accumulated and which are now registered with WHO. Before destruction is allowed, should there not be some test of the speed with which the intact virus could be regenerated?

There is also the issue of the route by which classical smallpox evolved its special virulence. To be sure, much may be learned from studies with other poxviruses, but authentic smallpox may be necessary at some stage. Destruction of existing stocks should be undertaken only when that important nugget of understanding has found its way into people's heads, and into the textbooks. But then it should be undertaken gleefully. Destruction then (as now) would be symbolic only, but it would be an important symbol of the eradication of risk from human life. Presumably even those who believe that biodiversity should be maximized would not object.

This double issue contains the complete index for 1993. Nature will not appear next week. The next issue will be dated 6 January 1994 . 